\title{
Lattice Dynamical, Elastic, Thermodynamic Properties and Sound Velocities of $3 \mathrm{C}-\mathrm{SiC}$
}

\author{
A.K. KUSHWAHA* \\ Department of Physics, K.N. Govt. P.G. College Gyanpur, Bhadohi-221304, India \\ (Received August 11, 2016; in final form March 29, 2018)
}

\begin{abstract}
We present a theoretical investigation of lattice dynamical properties, the zone boundary phonons, elastic properties, sound velocities and the Debye characteristic temperature for 3C-SiC using eleven parameter threebody shell model with both the ions polarizable. We compare our calculated results with the experimental and theoretical results.
\end{abstract}

DOI: 10.12693/APhysPolA.134.478

PACS/topics: silicon carbide, elastic properties, semiconductor, lattice dynamics, phonons

\section{Introduction}

Silicon carbide in cubic phase (3C-SiC) is a wide band gap semiconductor and has many technological applications in optoelectronic devices and for high-power, hightemperature applications due to its many unique properties such as low density, high strength, high melting point, high hardness large thermal conductivity, high breakdown voltage, and outstanding mechanical and chemical stability.

Recently, the lattice dynamical properties of $\mathrm{SiC}$ in zinc-blende (ZB) phase are studied by many researchers using first principles methods [1-4] and phenomenological models $[5,6]$. But the exact information about dynamical properties is still missing. Therefore in the present paper, we used eleven parameter three-body shell model with both the ions polarizable and investigated the lattice dynamical properties such as phonon dispersion relations, phonon density of states, variation of the Debye temperature with absolute temperature, zone-boundary phonons, elastic constants, mechanical properties of $\mathrm{SiC}$ in ZB phase.

\section{Potential model}

In three-body shell model proposed by Kushwaha [7], the harmonic potential energy per unit cell for ZB structure compounds can be written as

$$
\varphi=\varphi^{S M}+\varphi^{T B},
$$

where $\varphi^{S M}$ and $\varphi^{T B}$ are the potential energies of ZB structure compounds in the framework of rigid shell model (RSM) and three-body interaction, respectively.

The secular determinant, for determining the angular frequencies of vibration for the crystals may be obtained by solving the characteristic equation

$$
\left|D_{\alpha \beta}\left(\boldsymbol{q}, k k^{\prime}\right)-\omega^{2} \delta_{\alpha \beta} \delta_{k k}\right|=0
$$

for various wave vectors $\boldsymbol{q}$ in the reciprocal space. The

\footnotetext{
*e-mail: akkphys_bu@yahoo.com
}

symbols $k, k^{\prime}=1,2$ represent the type of atoms in the unit cell and $D_{\alpha \beta}\left(\boldsymbol{q}, k k^{\prime}\right)$ are the elements of dynamical matrix.

\section{Results and discussion}

\subsection{Lattice dynamical properties}

Our three-body shell model involved 11 parameters as $A, A_{1}, A_{2}, \gamma_{1}, \gamma_{2}, \gamma_{3}, \alpha_{1}, \alpha_{2}, d_{1}, d_{2}$ and $Z^{\prime}$, where $A, A_{1}$, and $A_{2}$ are two-body short-range parameters between $\mathrm{Si}-\mathrm{C}, \mathrm{Si}-\mathrm{Si}$, and $\mathrm{C}-\mathrm{C}$, respectively, $\gamma_{1}, \gamma_{2}$, and $\gamma_{3}$ are three two-body short-range parameters, $\alpha_{1}$ and $\alpha_{2}$ are electronic polarizbilities, $d_{1}$ and $d_{2}$ are distortion polarizabilities and $Z^{\prime}$ - effective charge parameter. The procedure of calculation of force parameters for $3 \mathrm{C}-\mathrm{SiC}$ is given elsewhere [7]. The input and calculated output parameters for the $3 \mathrm{C}-\mathrm{SiC}$ is shown in Table I. Using the eleven calculated parameters, we have calculated the phonon dispersion relations for $3 \mathrm{C}-\mathrm{SiC}$ in three high symmetry directions, as shown in Fig. 1, and these results

TABLE I

The input and output parameters for $3 \mathrm{C}-\mathrm{SiC}$

\begin{tabular}{r|l|r|l}
\hline \hline \multicolumn{2}{c|}{ Input parameter } & \multicolumn{2}{|c}{ Output parameter } \\
\hline$a$ & $4.40 \AA$ & $A$ & $150.28 \mathrm{kdyne} / \mathrm{cm}$ \\
$C_{11}$ & $390 \mathrm{Gdyne} / \mathrm{cm}^{2}$ & $\mathrm{~A}_{1}$ & $8.31 \mathrm{kdyne} / \mathrm{cm}$ \\
$C_{12}$ & $142 \mathrm{Gdyne} / \mathrm{cm}^{2}$ & $A_{2}$ & $25.22 \mathrm{kdyne} / \mathrm{cm}$ \\
$m_{1}$ & $26 \times 10^{-24} \mathrm{~g}$ & $\gamma_{1}$ & $4.21 \mathrm{kdyne} / \mathrm{cm}$ \\
$m_{2}$ & $12 \times 10^{-24} \mathrm{~g}$ & $\gamma_{2}$ & $2.89 \mathrm{kdyne} / \mathrm{cm}$ \\
$\omega_{L O}(\Gamma)$ & $9711 / \mathrm{cm}$ & $\gamma_{3}$ & $1.71 \mathrm{kdyne} / \mathrm{cm}^{3}$ \\
$\omega_{T O}(\Gamma)$ & $7951 / \mathrm{cm}$ & $\alpha_{1}$ & $0.34 \times 10^{-24} \mathrm{~cm}^{3}$ \\
$\omega_{L O}(X)$ & $8291 / \mathrm{cm}$ & $\alpha_{2}$ & $0.61 \times 10^{-24} \mathrm{~cm}^{3}$ \\
$\omega_{T O}(X)$ & $7601 / \mathrm{cm}$ & $d_{1}$ & 0.02 \\
$\varepsilon_{0}$ & 5.98 & $d_{2}$ & 0.05 \\
$\varepsilon_{\infty}$ & 6.52 & $Z^{\prime}$ & 0.81 \\
$e$ & $4.8 \times 10^{-10} \mathrm{esu}$ & &
\end{tabular}




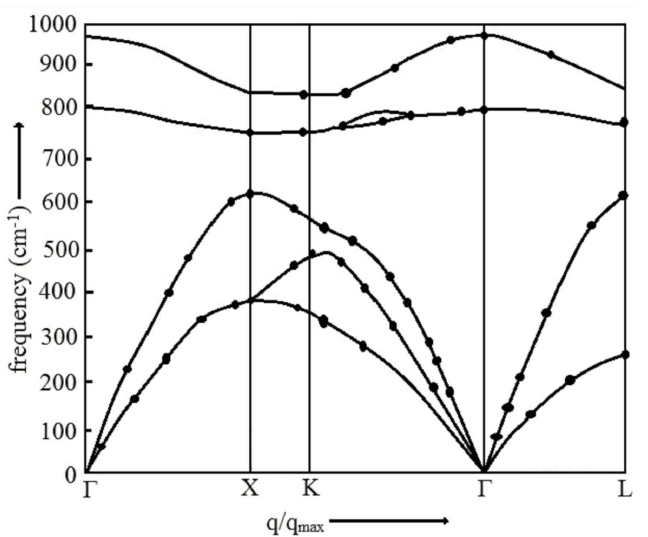

Fig. 1. Phonon dispersion relations $3 \mathrm{C}-\mathrm{SiC}$ along with the experimental results [2].

TABLE II

Zone-centre and zone-boundary phonons $\left[\mathrm{cm}^{-1}\right]$ for $3 \mathrm{C}$ SiC. First line - this work, second line experimental [7], third line calculation [8].

\begin{tabular}{r|c|c|c|c|c|c|c|c|c}
\hline \hline$\Gamma_{T O}$ & $\Gamma_{L O}$ & $X_{T O}$ & $X_{L O}$ & $X_{T A}$ & $X_{L A}$ & $L_{L A}$ & $L_{T A}$ & $L_{T O}$ & $L_{L O}$ \\
\hline 96 & 973 & 763 & 828 & 375 & 637 & 611 & 263 & 764 & 838 \\
795 & 972 & 760 & 829 & 372 & 639 & 610 & 261 & 765 & 837 \\
783 & 956 & 755 & 829 & 366 & 629 & 610 & 261 & 766 & 838
\end{tabular}

are in good agreement with the available experimental results [2]. We have also calculated the zone-centre and zone boundary phonons for $3 \mathrm{C}-\mathrm{SiC}$ and these are listed in Table II along with the previous experimental and theoretical data $[3,8]$.

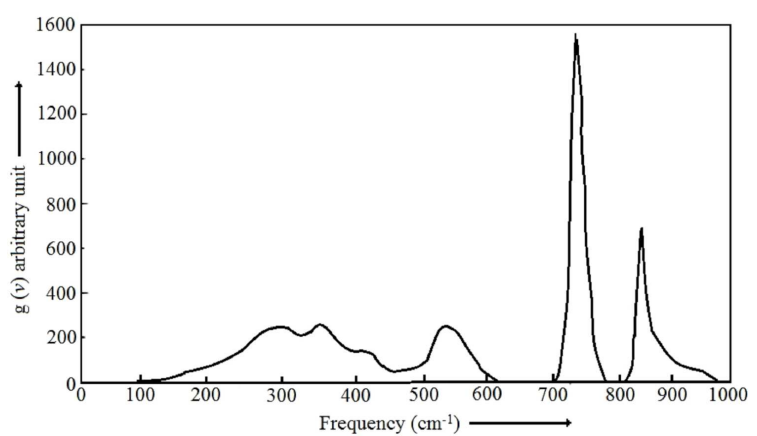

Fig. 2. Phonon density of states of 3C-SiC.

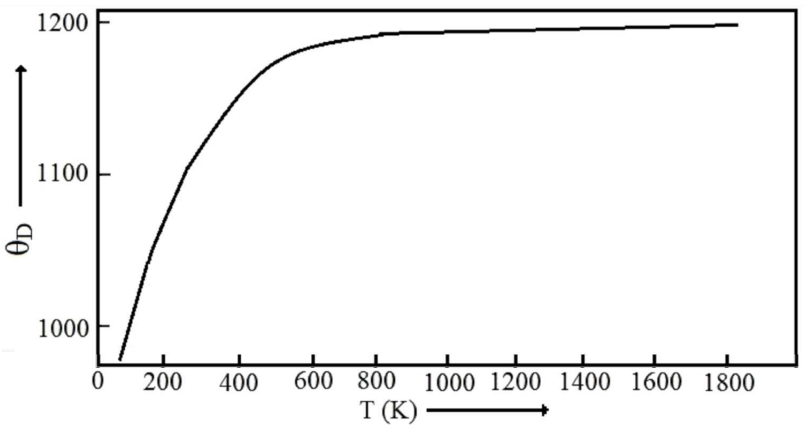

Fig. 3. $\Theta_{D}$ versus $T$ curve for $3 \mathrm{C}-\mathrm{SiC}$.
Phonon density of states has been calculated by the Blackman sampling technique [9]. For the calculation of phonon density of states and the Debye characteristics temperature we have used the method given in the literature [10]. The calculated phonon density of states and the variation of the Debye characteristics temperature with the absolute temperature are shown in Figs. 2 and 3 , respectively.

\subsection{Elastic and related properties}

For cubic systems, we have three elastic constants $C_{11}$, $C_{12}$, and $C_{44}$ and these are calculated by the method given in the literature [11]. The calculated elastic constants and related properties such as bulk modulus, compressibility, the Young modulus, shear modulus, the Poisson ratio and anisotropy factor are listed in Table III along with the previous experimental and theoretical results [12-38] available in the literature.

TABLE III

Calculated elastic constants $C_{11}, C_{12}$, and $C_{44}$ (GPa), bulk modulus $B(\mathrm{GPa})$, compressibility coefficient $K$ $\left(\mathrm{GPa}^{-1}\right)$, shear modulus $G(\mathrm{GPa})$, the Young modulus $Y(\mathrm{GPa})$, the Poisson ratio $\sigma$, anisotropy factor $A$ for $3 \mathrm{C}-\mathrm{SiC}$. First line - this work, lower lines — others.

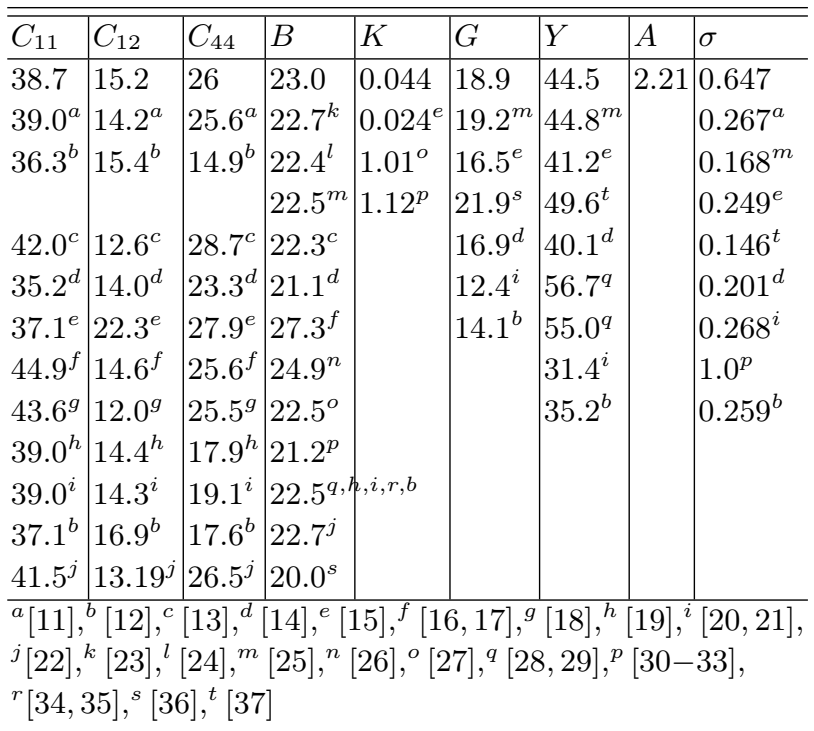

TABLE IV

Elastic wave velocities $[\mathrm{km} / \mathrm{s}]$ in various directions and the Debye temperature $[\mathrm{K}]$ for $3 \mathrm{C}-\mathrm{SiC}$. First line - this work.

\begin{tabular}{c|c|c|c|c|c|c|c|c|c|c}
\hline \hline$v_{L}^{[100]}$ & $v_{T}^{[100]}$ & $v_{l}^{[110]}$ & $v_{t}^{[110]}$ & $v_{t \perp}^{[110]}$ & $v_{v_{l^{\prime}}}^{[111]}$ & $v_{v_{t^{\prime}}}^{[111]}$ & $V_{L}$ & $V_{T}$ & $V_{m}$ & $\Theta_{D}$ \\
\hline 3.47 & 2.85 & 4.06 & 2.85 & 1.91 & 4.24 & 2.27 & 12.21 & 7.69 & 3.32 & 691 \\
& & & & & calc. & {$[32]$} & 12.40 & 7.17 & 16.88 & 612 \\
& & & & & calc. & {$[15]$} & 12.44 & 7.82 & 1.82 & 709 \\
& & & & & calc. & {$[39]$} & 12.18 & 7.70 & &
\end{tabular}

The calculated sound velocities along high symmetry directions and the Debye temperature for 3C-SiC are given in Table IV along with the previously calculated results $[32,15,39]$. 


\section{References}

[1] B.Y. Thakore, S.G. Khambholja, A.Y. Vahora, N.K. Bhatt, A.R. Jani, : 10.1088/16741056/22/10/106401.

[2] J. Serrano, J. Strempfer, M. Cardona, M.S. Bohning, H. Requardt, M. Lorenzen, B. Stojetz, P. Pavone, W.J. Choyke, Appl. Phys. Lett. 80, 4360 (2002).

[3] K. Karch, P. Pavone, W. Windl, O. Schutt, D. Strauch, Phys. Rev. B 50, 17054 (1994).

[4] L. Malakkal, B. Szpunar, R.K. Siripurapu, J.A. Szpunar, Comput. Mater. Sci. 128, 249 (2017).

[5] M. Hofmann, A. Zywietz, K. Karch, F. Bechstedt, Phys. Rev. B 50, 13401 (1994).

[6] P. Vashishta, R.K. Kalia, A. Nakano, J.P. Rino, J. Appl. Phys. 101, 103515 (2007).

[7] A.K. Kushwaha, Phys. Lett. A 372, 6145 (2008).

[8] D.W. Feldman, J.H. Parker, W.J. Choyke, L. Patrick, Phys. Rev. 173, 787 (1968).

[9] M. Blackman, Proc. R. Soc. A 159, 416 (1937).

[10] A.K. Kushwaha, Physica B 405, 1638 (2010).

[11] M. Born, K. Huang, Dynamical Theory of Crystal Lattices, Oxford University Press, Oxford 1954.

[12] D.W. Feldman, H. Parker, W. Choyke, L. Patric, Phys. Rev. 173, 787 (1968).

[13] D.H. Lee, J.D. Joannopoulos, Phys. Rev. Lett. 48, 1846 (1982).

[14] F.D. Murnaghan, Proc. Natl. Acad. Sci. USA 3, 244 (1944).

[15] K.B. Tolpygo, Sov. Phys. Solid State 2, 2367 (1961).

[16] D. Varshney, S. Shriya, M. Varshney, N. Singh, R. Khenata, J. Theor. Appl. Phys. 9, 221 (2015).

[17] W.J. Weber, N. Yu, L.M. Wang, N.J. Hess, J. Nucl. Mater. 244, 258 (1997).

[18] W.J. Weber, N. Yu, L.M. Wang, N.J. Hess, J. Mater. Sci. Eng. A 253, 62 (1998).

[19] M. Tang, S. Yip, J. Appl. Phys. 76, 2719 (1994).

[20] F. Shimojo, O.I. Ebbsj, R. Lalia, A. Nakano, J.P. Rino, P. Vashista, Phys. Rev. Lett. 84, 3338 (2000).
[21] P. Vashishta, R.K. Kalia, A. Nakano, J. Appl. Phys. 101, 103515 (2007).

[22] F.H. Stillinger, T.A. Weber, Phys. Rev. B 31, 5262 (1985).

[23] L.Y. Ping, H.D. Wei, Z. Jun, Y.X. Dong, Physica B 403, 3543 (2008).

[24] I.V. Aleksandrov, A.F. Goncharov, S.M. Stishov, E.V. Yakovenko, J. Exp. Theor. Phys. Lett. 50, 127 (1989).

[25] D.H. Yean Jr., J.R. Writer, J. Phys. Chem. Solids 32, 653 (1971).

[26] R.D.J. Carnahan, J. Am. Ceram. Soc. 51, 223 (1968).

[27] S.O. Lundqvist, Ark. Fys. 12, 263 (1957).

[28] N. Churcher, K. Kunc, V. Heine, J. Phys. C 19, 4413 (1986).

[29] K.J. Chang, M.L. Cohen, Phys. Rev. B 35, 8196 (1987).

[30] B.H.K. Cheong, J. Chang, M.L. Cohen, Phys. Rev. B 44, 1053 (1991).

[31] W.J. Weber, N. Yu, L.M. Wang, N.J. Hess, J. Nucl. Mater. 244, 258 (1997).

[32] M. Tang, S. Yip, J. Appl. Phys. 76, 2719 (1994).

[33] W.J. Weber, N. Yu, L.M. Wang, N.J. Hess, J. Mater. Sci. Eng. A 253, 62 (1998).

[34] F. Gao, W.J. Weber, Phys. Rev. B 69, 224108 (2004).

[35] M. Durandurdu, D.A. Drabold, Phys. Rev. B 75 , 235204 (2007).

[36] M. Durandurdu, J. Phys. C 16, 4411 (2004).

[37] P.J.H. Denteneer, W.V. Haeringen, Phys. Rev. B 33, 2831 (1986).

[38] W.R.L. Lambrecht, B. Segall, M. Methfessel, M.V. Schilfgaarde, Phys. Rev. B 44, 3685 (1991).

[39] E. Schreiber, O.L. Anderson, N. Soga, Elastic Constants and Their Measurement, McGraw-Hill, New York 1973.

[40] M. Takahiro, N. Tetsuro, N. Yasuaki, K. Katsuhiro, Y. Tastuya, N. Hidetoshi, N. Satoshi, J. Am. Ceram. Soc. 84, 1521 (2001). 